Article

\title{
Evaluation of Symbiotic Association between Various Rhizobia, Capable of Producing Plant-Growth-Promoting Biomolecules, and Mung Bean for Sustainable Production
}

\author{
Abid Mahmood 1,2,*, Tanvir Shahzad ${ }^{1}$, Sabir Hussain ${ }^{1}$, Qasim Ali ${ }^{3}$, Hayssam M. Ali ${ }^{4}{ }^{\oplus}$, Sanaullah Yasin ${ }^{5}$, \\ Muhammad Ibrahim ${ }^{1, *}$, Mohamed Z. M. Salem ${ }^{6}{ }^{\infty}$ and Muhammad Khalid ${ }^{3}$ \\ 1 Department of Environmental Sciences and Engineering, Government College University Faisalabad, \\ Faisalabad 38000, Pakistan; tanvirshahzad@gcuf.edu.pk (T.S.); sabir.hussain@gcuf.edu.pk (S.H.) \\ 2 Department of Land, Air and Water Resources, University of California, Davis, CA 95616, USA \\ 3 Institute of Soil and Environmental Sciences, University of Agriculture, Faisalabad 38040, Pakistan; \\ qasim.ali@uaf.edu.pk (Q.A.); drkhaliduaf@yahoo.com (M.K.) \\ 4 Botany and Microbiology Department, College of Science, King Saud University, P.O. Box 2455, \\ Riyadh 11451, Saudi Arabia; hayhassan@ksu.edu.sa \\ 5 Cotton Research Station Ghotki, Pakistan Central Cotton Committee Multan, Multan 66000, Pakistan; \\ sanaullahyasin@gmail.com \\ 6 Forestry and Wood Technology Department, Faculty of Agriculture (EL-Shatby), Alexandria University, \\ Alexandria 21545, Egypt; zidan_forest@yahoo.com \\ check for \\ updates \\ * Correspondence: drabid@gcuf.edu.pk (A.M.); ebrahem.m@gmail.com (M.I.); Tel.: +1-530-302-6936 (A.M.)
}

Citation: Mahmood, A.; Shahzad, T.; Hussain, S.; Ali, Q.; Ali, H.M.; Yasin, S.; Ibrahim, M.; Salem, M.Z.M.; Khalid, M. Evaluation of Symbiotic Association between Various Rhizobia, Capable of Producing Plant-Growth-Promoting Biomolecules, and Mung Bean for Sustainable Production. Sustainability 2021, 13, 13832. https://doi.org/ $10.3390 /$ su132413832

Academic Editors: Manuel González de Molina and Roberto Mancinelli

Received: 4 September 2021

Accepted: 13 December 2021

Published: 14 December 2021

Publisher's Note: MDPI stays neutral with regard to jurisdictional claims in published maps and institutional affiliations.

Copyright: () 2021 by the authors. Licensee MDPI, Basel, Switzerland. This article is an open access article distributed under the terms and conditions of the Creative Commons Attribution (CC BY) license (https:// creativecommons.org/licenses/by/ $4.0 /)$.
Abstract: To feed the increased world population, sustainability in the production of crops is the need of the hour, and exploration of an effective symbiotic association of rhizobia with legumes may serve the purpose. A laboratory-scale experiment was conducted to evaluate the symbiotic effectiveness of twenty wild rhizobial isolates (MR1-MR20) on the growth, physiology, biochemical traits, and nodulation of mung bean to predict better crop production with higher yields. Rhizobial strain MR4 resulted in a 52\% increase in shoot length and $49 \%$ increase in shoot fresh mass, while MR5 showed a $30 \%$ increase in root length, with $67 \%$ and $65 \%$ improvement in root fresh mass by MR4 and MR5, respectively, compared to uninoculated control. Total dry matter of mung bean was enhanced by $73 \%$ and $68 \%$ with strains MR4 and MR5 followed by MR1 and MR3 with $60 \%$ increase in comparison to control. Rhizobial strain MR5 produced a maximum ( 25 nodules) number of nodules followed by MR4, MR3, and MR1 which produced 24, 23, and 21 nodules per plant. Results related to physiological parameters showed the best performance of MR4 and MR5 compared to control among all treatments. MR4 strain helped the plants to produce the lowest values of total soluble protein (TSP) (38\% less), flavonoids contents (44\% less), and malondialdehyde (MDA) contents (52\% less) among all treatments compared to uninoculated control plants. Total phenolics contents of mung bean plants also showed significantly variable results, with the highest value of $54.79 \mathrm{mg} \mathrm{kg}^{-1}$ in MR4 inoculated plants, followed by MR5 and MR1 inoculated plants, while the minimum concentration of total phenolics was recorded in uninoculated control plants of mung bean. Based on the results of growth promotion, nodulation ability, and physiological and biochemical characteristics recorded in an experimental trial conducted under gnotobiotic conditions, four rhizobial isolates (MR1, MR3, MR4, and MR5) were selected using cluster and principal component analysis. Selected strains were also tested for a variety of plant-growth-promoting molecules to develop a correlation with the results of plant-based parameters, and it was concluded that these wild rhizobial strains were effective in improving sustainable production of mung bean.

Keywords: rhizobia; mung bean; nodules; TSP; flavonoids; MDA; total phenolics 


\section{Introduction}

The global increase in human population and consequences of environmental damages have been indicating that global food production may soon be insufficient to feed all of the world's population. Therefore, it is necessary to sustainably increase agricultural productivity to produce enough food to meet the needs of the world [1]. Use of plant-growth-promoting microorganisms, especially bacteria, is one of the sustainable agricultural practices which benefit the plants either as free-living cells or by endophytic and symbiotic mechanisms [2]. Plant-growth-promoting bacteria (PGPB) can operate directly by assisting in the uptake of nutrients or regulating plant hormone levels, or indirectly by reducing pathogen inhibitory effects [3]. Rhizobia are bacterial symbionts of legumes that fix nitrogen from the atmosphere through a process called biological nitrogen fixation (BNF). A complicated biochemical dialogue takes place in the early phases of the symbiosis, involving Nod factors generated by the bacterium and flavonoids secreted by legume roots, for mutual recognition for nodulation to occur [4]. Rhizobia can metabolize ambient nitrogen in root nodules and convert it into plant-available nitrogenous compounds. This process reduces the application of nitrate fertilizers and results in cost saving for both the environment and the farmer [5]. Subsequent crops may also enjoy the benefits of the BNF produced by the symbiosis of legume and rhizobia along with the host crop [6].

Due to this logic, legume-rhizobium mutualism has been extensively investigated as a paradigm of mutualistic associations for sustainable agriculture. Legume-rhizobium mutualism is very particular, as every strain of rhizobia has its own specific host range that can be very broad or narrow $[7,8]$. For specific environmental situations and soil types, it is preferable to select bacterial strains specific to distinct cultivars of the leguminous host [9]. In addition to nitrogen fixation, some other mechanisms of plant growth promotion are also reported by Chernin and Glick [10]. Among these mechanisms, an exhibition of desirable traits of physiology by some rhizobia like production of plant-growth-promoting molecules including gibberellins, lumichrome, cytokinins, riboflavin, indole-3-acetic acids (IAA), 1-aminocyclopropane-1-carboxylate (ACC) deaminase, protons for phosphate solubilization, and Nod factors, which result in plant growth and productivity through diversified roles [11-13].

In higher plants, the enzyme ACC deaminase can reduce harmful quantities of ethylene, leading to enhanced output. There are two unique biochemicals found in rhizobial exudates that are known to enhance plant growth: lumichrome and riboflavin. IAA, on the other hand, is a member of the auxin family that regulates plant physiological processes such as cell division and expansion, differentiation of tissue and responses to light/gravity $[14,15]$. Furthermore, it is also a proven fact that rhizobia impart enhanced resistance in plants against disease-causing organisms [16]. Mung bean, one of the legumes, is capable of fixing atmospheric nitrogen via its symbiont, Rhizobium phaseoli, and shows increased photosynthetic rate, leaf area, plant height, and biomass production when inoculated with Rhizobium species living in root nodules. However, under arid and semi-arid agro-ecological conditions, the nodulation of the mung bean is poor and is a major cause of its lower yield [17]. In Pakistan, the mung bean contribution is $16 \%$ of the total production of pulses as grown on $15 \%$ of the area of total pulses-occupied area, but its production is not appropriate due to lack of effective symbiotic associations [18].

Keeping in view the above-mentioned facts, the present study was designed to find out the symbiotic effectiveness of wild rhizobial strains (twenty strains) based on growth promotion, nodulation, and improvement of physiological and biochemical attributes of mung bean. As a result, assessment of the biochemical characteristics of the best-performing wild rhizobial strains under controlled conditions to predict sustainability in the production and yield of mung bean is also part of this research. 


\section{Materials and Methods}

\subsection{Isolation and Preservation of Rhizobial Isolates}

Numerous rhizobia were isolated from the root nodules of mung bean (Vigna radiata L.) plants sampled from different fields of District Faisalabad, Pakistan. Root samples in polythene bags were transferred to the laboratory where the standard protocol was followed before and after cutting nodules and using $5 \%$ sodium hypochlorite for surface disinfection purposes, followed by washing with sterilized distilled water [19]. After surface disinfection, a suspension was prepared following standard procedures. Yeast extract mannitol agar (YEM) media was prepared (mannitol, $15 \mathrm{~g}$; yeast extract, $0.5 \mathrm{~g}$; $\mathrm{K}_{2} \mathrm{HPO}_{4}, 0.5 \mathrm{~g} ; \mathrm{MgSO}_{4} .7 \mathrm{H}_{2} \mathrm{O}, 0.2 \mathrm{~g} ; \mathrm{NaCl} 0.1 \mathrm{~g}$ with $\mathrm{pH}$ adjusted to 7.0 ) and autoclaved. These agar plates were inoculated by using $1 \mathrm{~mL}$ of above-prepared suspension and incubated at $28 \pm 1{ }^{\circ} \mathrm{C}$ for 48 hours to obtain bacterial growth. Fast-growing colonies of rhizobia were selected and purified by streaking (3-4 times) on fresh agar plates of YEM. Twenty fast-growing strains were selected, coded (MR1 to MR20), and preserved at $4{ }^{\circ} \mathrm{C}$ for subsequent use. Fresh inocula of MR1-MR20 was prepared by using YEM broth, which was pre-sterilized and incubated at $28 \pm 1{ }^{\circ} \mathrm{C}$ at $180 \mathrm{rpm}$ for $48 \mathrm{~h}$. After achieving cell density of $10^{8}-10^{9} \mathrm{CFU} \mathrm{mL} \mathrm{m}^{-1}$, the inocula were assumed ready for inoculation. For seed (mung bean NM-2006) inoculation with twenty strains, inoculated peat mixed with clay and 10 percent sugar solution were used for seed dressing. Non-inoculated control seeds used the same broth but after autoclaving.

\subsection{Experimental Setup and Growth Attributes}

The impact of twenty rhizobial isolates (MR1-MR20) on mung bean growth, physiology, biochemical characteristics, and nodulation was evaluated in a laboratory-scale jar experiment. The plastic jars were filled with sand and autoclaved twice before being placed in the growth room. In each plastic jar, five inoculated NM-2006 mung bean seeds were sowed. Six replicates of each experimental unit were performed using a completely randomized design (CRD), with the control being treated with sterilized broth. For irrigation, a nitrogen-free Hoagland solution at half strength was utilized. After five weeks of seeding, biomass production was assessed in terms of shoot/root fresh mass and total dry matter. The roots and shoots of the seedlings were separated, and their fresh weights were determined. A 48-h oven drying period at $70{ }^{\circ} \mathrm{C}$ was used to determine the dry biomass.

\subsection{Physiological and Photosynthetic Attributes}

In each experimental unit, two completely expanded leaves from one plant were selected and portable infra-red gas analyzer (IRGA) was used to measure different physiological parameters including sub-stomatal $\mathrm{CO}_{2}$ concentration $(\mathrm{Ci})$, photosynthetic rate (A), transpiration (E), and stomatal conductance of water (gs). Morning time was selected for the measurement of these physiological parameters at $1200-1400 \mu \mathrm{mol} \mathrm{m}^{-2} \mathrm{~s}^{-1}$ photosynthetic photon flux density [20]. SPAD chlorophyll meter SPAD-502 (Minolta, Minolta Co, Ltd., UK) was used to measure SPAD chlorophyll contents in the leaves of mung bean plant [21].

The method reported by Arnon [22] was used to determine chlorophyll a and b. For extraction, $80 \%$ acetone was used on $50 \mathrm{mg}$ of fresh leaf sample using mortar and pestle, followed by filtration and $50 \mathrm{~mL}$ volume formation by diluting with $80 \%$ acetone. For the measurement of chlorophyll a and b, $645 \mathrm{~nm}$ and $663 \mathrm{~nm}$ wavelengths, respectively, were used to measure absorbance of diluted plant extract. The following equations were used to calculate the values of chlorophyll $\mathrm{a}$ and $\mathrm{b}$ :

$$
\begin{aligned}
& \text { Chlorophyll a }\left(\mathrm{mg} \mathrm{g}^{-1} \mathrm{FW}\right)=\frac{12.7 \mathrm{~A}_{663}-2.69 \mathrm{~A}_{645}}{1000 \times \mathrm{W}} \times \mathrm{V} \\
& \text { Chlorophyll b }\left(\mathrm{mg} \mathrm{g}^{-1} \mathrm{FW}\right)=\frac{22.9 \mathrm{~A}_{645}-4.68 \mathrm{~A}_{663}}{1000 \times \mathrm{W}} \times \mathrm{V} .
\end{aligned}
$$


where $\mathrm{V}=$ volume of extract in $\mathrm{ml}$, and $\mathrm{W}=$ fresh weight of leaf sample in grams.

The method described by Aery [23] was used to determine total carotenoid contents of mung bean leaves. Fresh leaf sample $(50 \mathrm{mg}$ ) was ground with $80 \%$ acetone in mortar and pestle, and was then filtered and diluted using $80 \%$ acetone to make a volume of $25 \mathrm{~mL}$. This diluted volume was checked for absorbance at 480 and $510 \mathrm{~nm}$, respectively. For the estimation of carotenoid contents, the following equation was used:

$$
\text { Carotenoid contents }\left(\mathrm{mg} \mathrm{g}^{-1} \mathrm{FW}\right)=\frac{7.6 \mathrm{D}_{480}-1.4 \mathrm{D}_{510}}{1000 \times \mathrm{W}} \times \mathrm{V}
$$

where $\mathrm{D}=\mathrm{OD}$ at specific wavelength, $\mathrm{V}=$ volume of extract in $\mathrm{mL}$, and $\mathrm{W}=$ fresh weight of leaf sample in grams.

\subsection{Extraction of Enzymes, Determination of Total Soluble Protein (TSP) Content and Malondialdehyde (MDA) Content}

An ice-cold buffer solution containing $1.5 \mathrm{~g}$ insoluble PVP, $2 \mathrm{ml} \mathrm{L}^{-1}$ Triton X-100, $10 \mathrm{mM}$ d-isoascorbic acid, $20 \mathrm{~g} \mathrm{~L}^{-1}$ PVP-10, $0.1 \mathrm{mM}$ EDTA, and $100 \mathrm{mM}$ Tris (pH 7.0) was used to homogenize $0.5 \mathrm{~g}$ of frozen fresh seedlings to extract the antioxidant enzyme. Bradford's method [24] was used to calculate quantitative TSP using bovine serum albumin (BSA) as a reference. MDA concentration in seedlings as a measure of lipid peroxidation was determined with some minor adjustments to it [25].

\subsection{Biomolecular Characterization and Identification of Selected Rhizobial Isolates}

The best-performing rhizobial isolates were selected and characterized for different plant-growth-promoting properties, and their identification was confirmed. The ability of selected rhizobial isolates to produce indole 3 -acetic acid (IAA) in the presence and absence of substrate (L-TRP) was determined spectrophotometrically [26]. The method described by Borrow et al. [27] was used to estimate the production of gibberellins (GA) by shortlisted strains. Using naringenin as a standard, the total flavonoid content was calculated using the aluminum chloride method [28]. At $510 \mathrm{~nm}$, the absorbance was measured. The plate test method [29] was adopted to determine that the best-performing rhizoia can solubilize $\mathrm{ZnO}$ and $\mathrm{ZnCO}_{3}$ in vitro. On National Botanical Research Institute Phosphate Bromophenol Blue (NBRI-PBB) media, the solubilization of inorganic phosphate by chosen rhizobia was investigated [30]. The formula of Ramesh et al. [31] was used for the determination of zinc and phosphorus solubilization index. Siderophore production assay was performed on selected strains by following the method of Schwyn and Neilands [32]. Fresh inoculum for each selected isolate was used for exopolysaccharide production assay [33], while chitinase, catalase, and oxidase activities were tested by the methods of [34,35], respectively. The procedure mentioned by Nutman [36] was adopted to perform an organic acid production assay.

\subsection{Statistical Analyses}

One-way analysis of variance technique (ANOVA) described by Steel et al. [37] was used to examine the data, and Tukey's test was used to compare means, while Statistix 8.1 was utilized for the analysis (Analytical Software, USA). For principal component analysis (PCA), XLSTAT software (v.4.04) was used, while Minitab software (Minitab ${ }^{\mathrm{TM}}$ version 16) was utilized for cluster analysis.

\section{Results}

\subsection{Plant and Biomass Growth, and Nodulation of Mung Bean}

A growth room experiment under controlled conditions was conducted to evaluate the effect of different wild rhizobial strains on the growth, physiology, nodulation, antioxidants enzymes, and biomass of mung bean to select the best-performing rhizobial strains for further experimentation. Growth data of mung bean presented in Figure 1 show that 9 out of 20 rhizobial strains significantly increased shoot length as compared to uninoculated 
control. Rhizobial strain MR4 gave the maximum increase (52\% over control) in shoot length, followed by MR5, MR1, and MR3 with 47, 46, and 39\% increase, respectively, as compared to uninoculated control (Figure 1a).
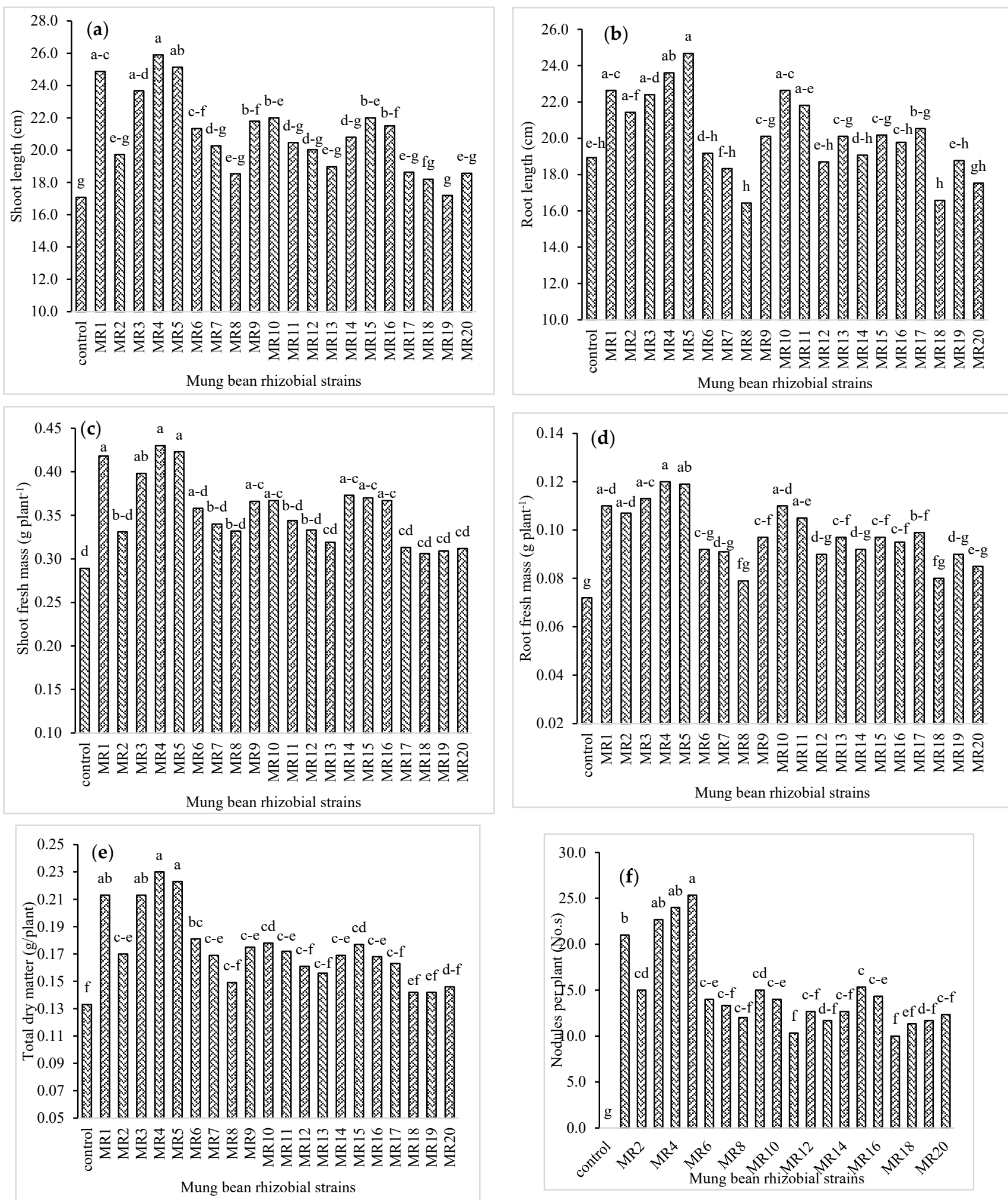

Figure 1. Impact of rhizobial inoculation on growth attributes of mung bean under gnotobiotic conditions: (a) shoot length; (b) root length; (c) shoot fresh mass; (d) root Fresh mass; (e) total dry matter; (f) number of nodules per plant (average of 3 replicates). Means sharing the same letters are statistically at par where $p=0.05$. 
Rhizobial strains MR10, MR15, MR9, MR16, and MR6 were statistically non-significant when compared with one another but caused significant improvement in shoot length of mung bean by $29,29,28,26$, and $25 \%$, respectively, compared to uninoculated control (Figure 1a).

The significant increase in root length due to the five rhizobial strains (MR1, MR3, MR4, MR5, and MR10) ranged from 18 to 30\% compared to the uninoculated control. Rhizobial strain MR5 gave a maximum increase (30\%) in root length, followed by MR4 with an increase of 25\% (Figure 1b). The strains MR1 and MR10 resulted in 20\% increase each compared to uninoculated control, and were followed by strain MR3, which caused $18 \%$ increase in root length compared to control (Figure 1b). Rhizobial strain MR4 gave the maximum increase (49\%) in shoot fresh mass compared to uninoculated control, followed by MR5, MR1, and MR3 with 46, 45, and 38\% increase in shoot fresh mass of mung bean, respectively, as compared to uninoculated control (Figure 1c). Rhizobial strains MR14 and MR15 caused significant improvement in shoot fresh mass of mung bean by 29 and $28 \%$, respectively, compared to uninoculated control (Figure 1c). A similar trend was observed regarding root fresh mass, where rhizobial strain MR4 and MR5 gave the maximum increase (67 and 65\% compared to uninoculated control, respectively), followed by MR3 with $57 \%$ increase in root fresh mass of mung bean as compared to uninoculated control (Figure 1d). A significant increase of 53\% each was also observed due to inoculation of MR1 and MR10 in comparison to uninoculated control, followed by MR2, MR11, and MR17 with an improvement of 49, 46, and 38\%, respectively (Figure 1d).

Overall, 13 rhizobial strains out of 20 significantly increased total dry matter as compared to uninoculated control, while 7 other strains non-significantly increased total dry matter as compared to uninoculated control (Figure 1e). Increases in total dry matter of 73 and $68 \%$ were recorded in plants inoculated with strains MR4 and MR5, followed by MR1 and MR3 with 60\% increase as compared to uninoculated control. Rhizobial strains MR6, MR10, MR15, MR9, MR11, and MR2 significantly improved total dry matter by 36, 34, $33,32,29$, and $28 \%$, respectively, as compared to uninoculated control, but their effect was non-significant as compared to each other (Figure 1e). All 20 rhizobial strains significantly increased nodulation as compared to uninoculated control, as nodulation did not occur in sterilized uninoculated control, while rhizobial strain MR5 produced maximum (25 nodules) number of nodules followed by MR4, MR3, and MR1, which produced 24, 23, and 21 nodules per plant (Figure 1f). Sixteen other rhizobial strains produced nodules with a range of 10-15 nodules per plant, while the minimum (10 nodules) number of nodules per plant was recorded due to the inoculation of rhizobial strains MR11 and MR17 (Figure 1f).

\subsection{Physiological Attributes of Mung Bean}

Figure 2 represents data of physiological parameters of the mung bean plants affected by the inoculation of wild rhizobial strains. Plants inoculated with MR5 strain showed $31 \%$ higher values of sub-stomatal carbon dioxide concentration ( $\mathrm{Ci}$ ) as compared to uninoculated plants (Figure 2a). Similar kinds of results were observed in the plants which were inoculated with MR4, MR3, and MR1, with concentrations of sub-stomatal $\mathrm{CO}_{2}$ ranging from 22 to $30 \%$ more compared to control plants. It is also depicted in Figure $2 \mathrm{~b}$ that significantly higher values of assimilation rate $(A)$, stomatal conductance $\left(g_{s}\right)$ (Figure $\left.2 c\right)$, and transpiration (E) (Figure 2d) were shown by those plants which were inoculated with MR4, MR5, MR3, and MR1. Sixteen other strains also produced better plants with positive values of physiology, but those values were non-significant as compared to the aforementioned four best strains. 

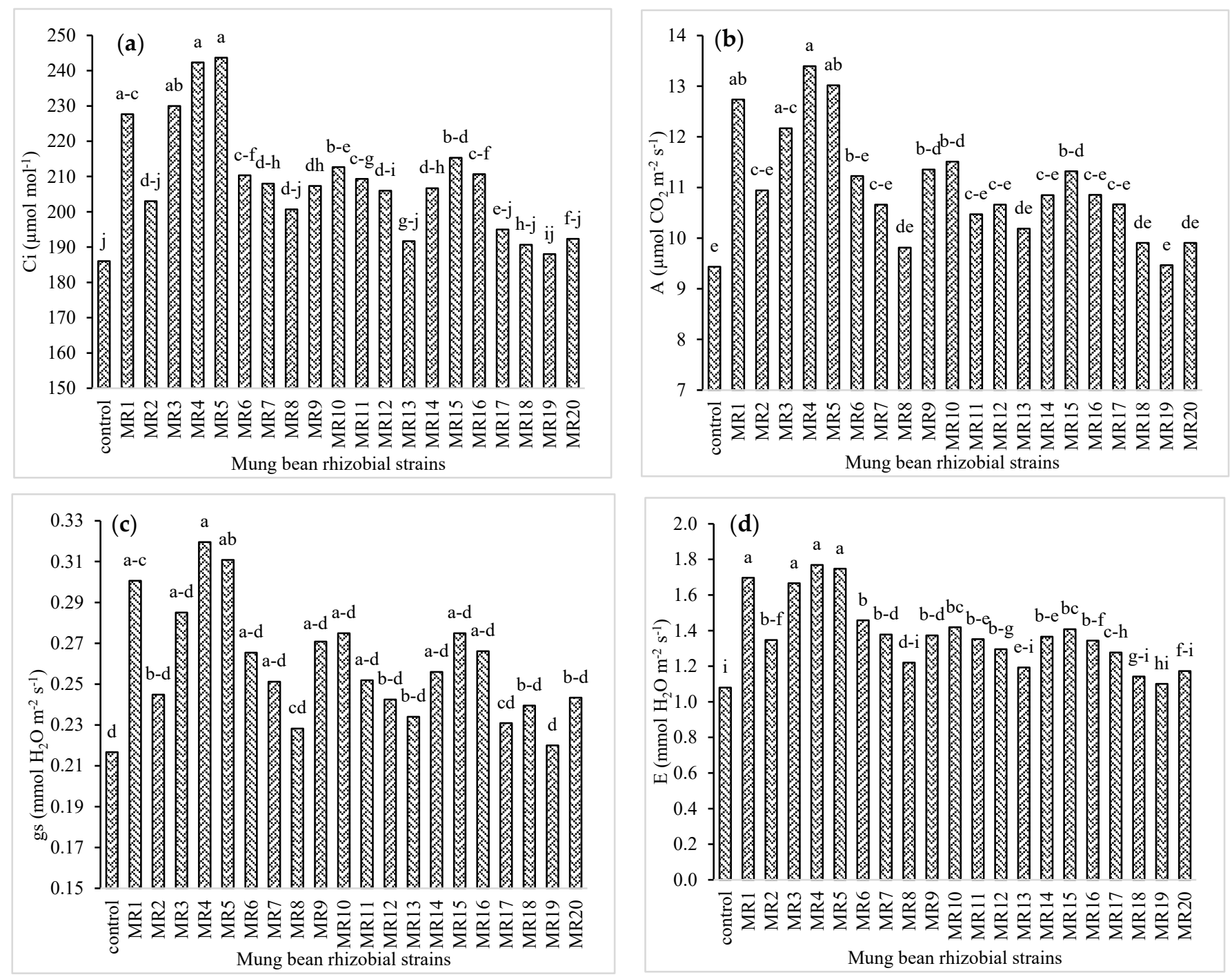

Figure 2. Impact of rhizobial inoculation on physiological attributes of mung bean under gnotobiotic conditions: (a) sub-stomatal $\mathrm{CO}_{2}$ concentration (Ci); (b) assimilation (A); (c) stomatal conductance (gs); (d) transpiration (E) (average of 3 replicates). Means sharing same letters are statistically at par where $p=0.05$.

\subsection{Photosynthetic Attributes of Mung Bean}

SPAD chlorophyll, chlorophyll a, chlorophyll $b$, and total carotenoids' data is given in Figure $3 a-d$, which indicates that all the strains performed better when seen in reference to control, while significantly higher and best performance was shown by the strains MR4, MR5, MR3, and MR1. SPAD chlorophyll values of these four best strains ranged from 42 to $54 \%$ better compared to uninoculated plants (Figure $3 a$ ). Figure $3 \mathrm{~b}$ shows that chlorophyll a values of all the plants inoculated with rhizobium ranged from 1.11 to $1.60 \mathrm{mg} \mathrm{g}^{-1} \mathrm{FW}$, while that of control plant chlorophyll a was $1.04 \mathrm{mg} \mathrm{g}^{-1} \mathrm{FW}$. Results demonstrated that the best value of chlorophyll a was produced by inoculation of strain MR4, with $54 \%$ higher values compared to uninoculated controlled, followed by MR5, MR1, and MR3 with 51\%, $44 \%$, and $44 \%$ higher values compared to control plants. Data regarding chlorophyll b (Figure 3c) indicates an almost similar trend as chlorophyll a, but the results were much better in terms of percentages, with the highest value produced by MR4, which was $89 \%$ more in comparison to uninoculated control plants. MR5-inoculated plants produced $85 \%$ more chlorophyll $b$ compared to control, while the overall range of chlorophyll $b$ in inoculated plants was 1.047 to $1.643 \mathrm{mg} \mathrm{g}^{-1} \mathrm{FW}$. Data regarding total carotenoids present in plants is presented in Figure 3d, which shows that the best results were found in those 
plants which were inoculated by MR4, MR5, MR1, and MR3 with values $64 \%, 63 \%$, 55\%, and $54 \%$, respectively, higher compared to uninoculated control.
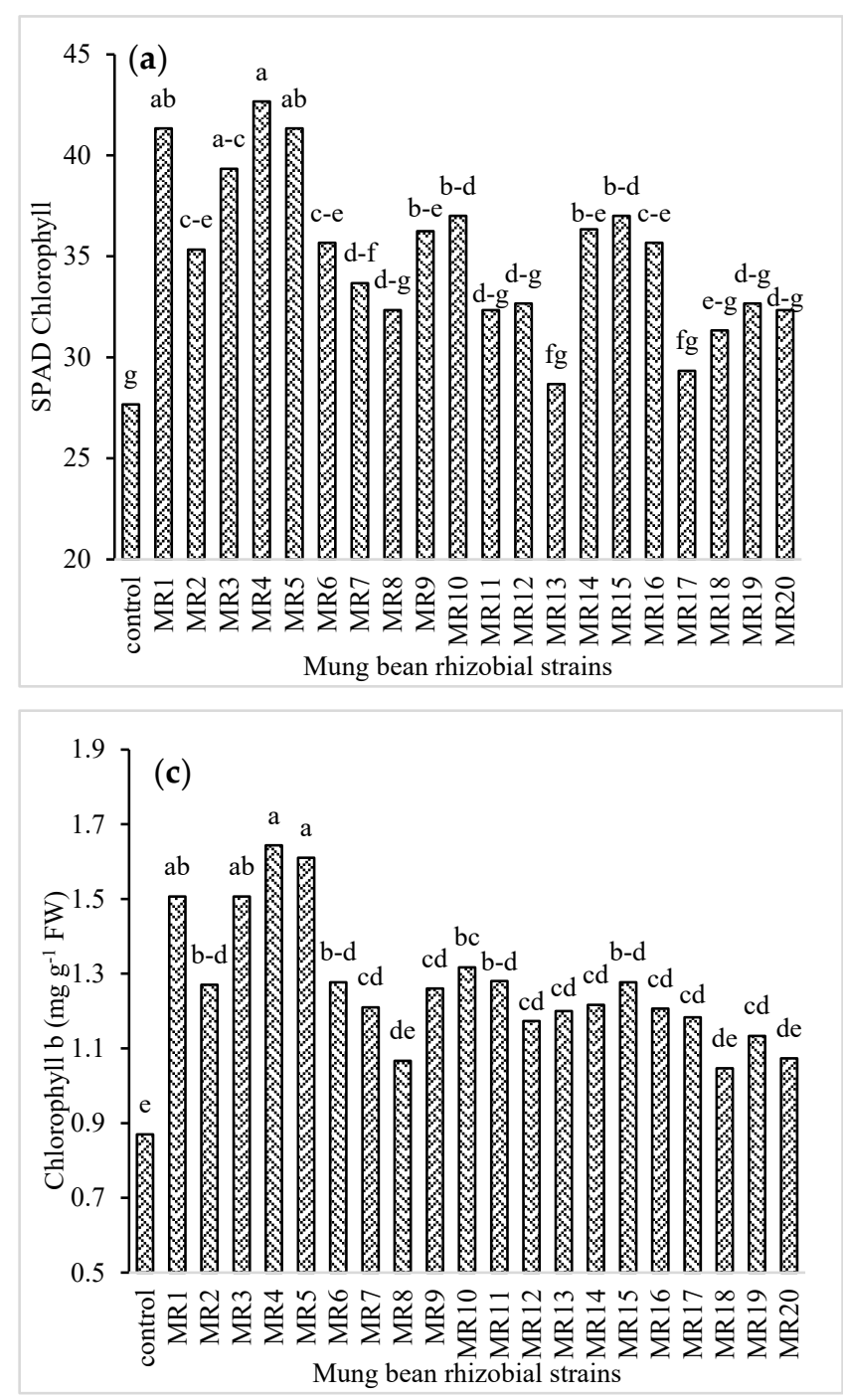
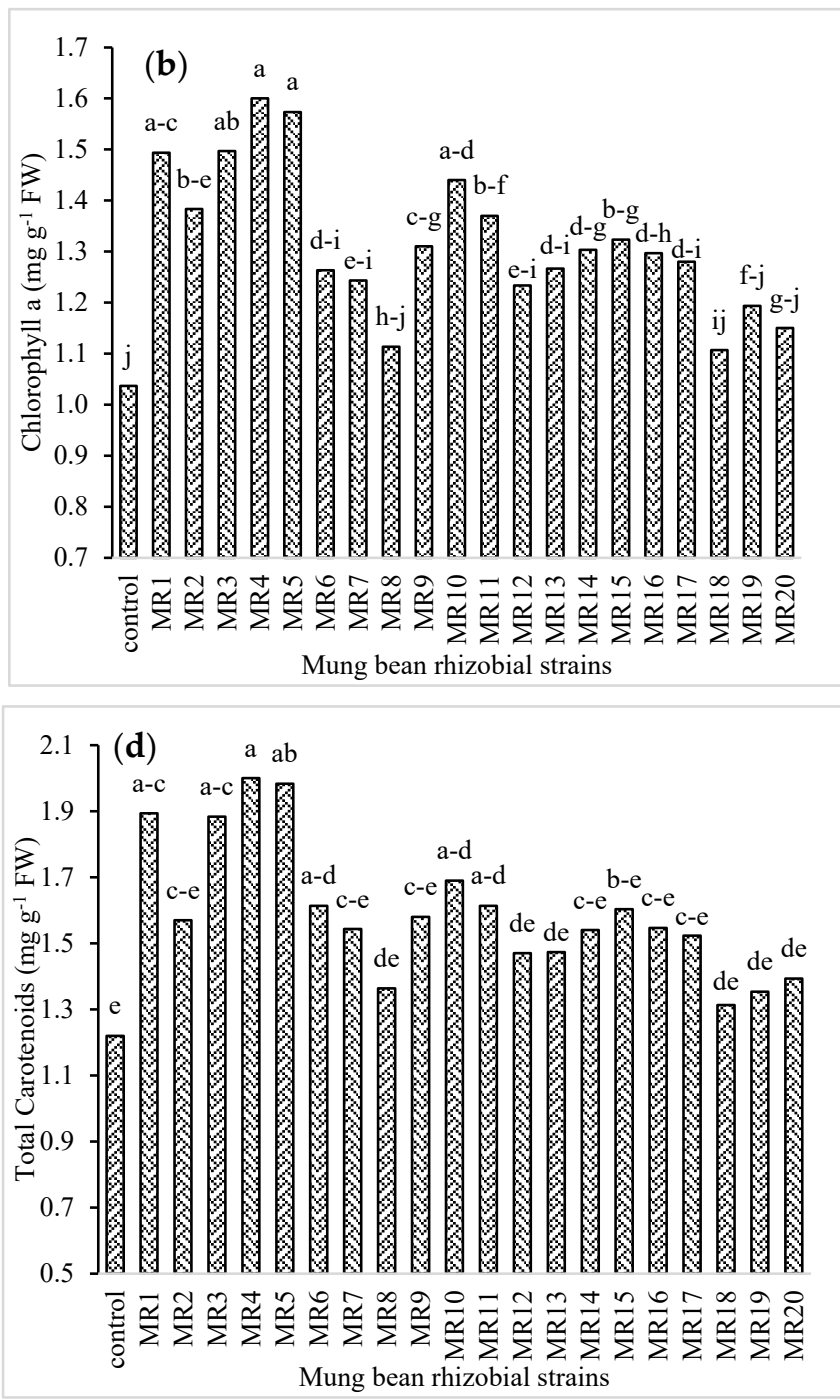

Figure 3. Impact of rhizobial inoculation on photosynthetic attributes of mung bean under gnotobiotic conditions: (a) SPAD chlorophyll; (b) chlorophyll a; (c) chlorophyll b; (d) total carotenoids (average of 3 replicates). Means sharing the same letters are statistically at par where $p=0.05$.

\subsection{Biochemical Properties of Mung Bean}

Data presented in Figure 4a shows that significant differences in the values of total soluble proteins (TSP) were observed, where plants inoculated with MR4 strain produced the lowest values of TSP among all treatments, and this was 38\% less than the uninoculated control plants, which produced the highest value of TSP. Total phenolics contents of mung bean plants also showed significantly variable results, with the highest value of $54.79 \mathrm{mg} \mathrm{kg}^{-1}$ in MR4-inoculated plants, followed by MR5- and MR1-inoculated plants, while the minimum concentration of total phenolics was recorded in uninoculated control plants of mung bean (Figure $4 \mathrm{~b}$ ). Results regarding flavonoids contents of mung bean plants (Figure 4c) showed an almost similar trend to TSP, where MR4 inoculation helped to produce $44 \%$ less contents of flavonoids as compared to uninoculated ones, followed by MR5 ( $43 \%$ less), MR1 (38\% less), and MR3 (34\% less), while highest flavonoid contents were recorded in uninoculated control plants of mung bean. 

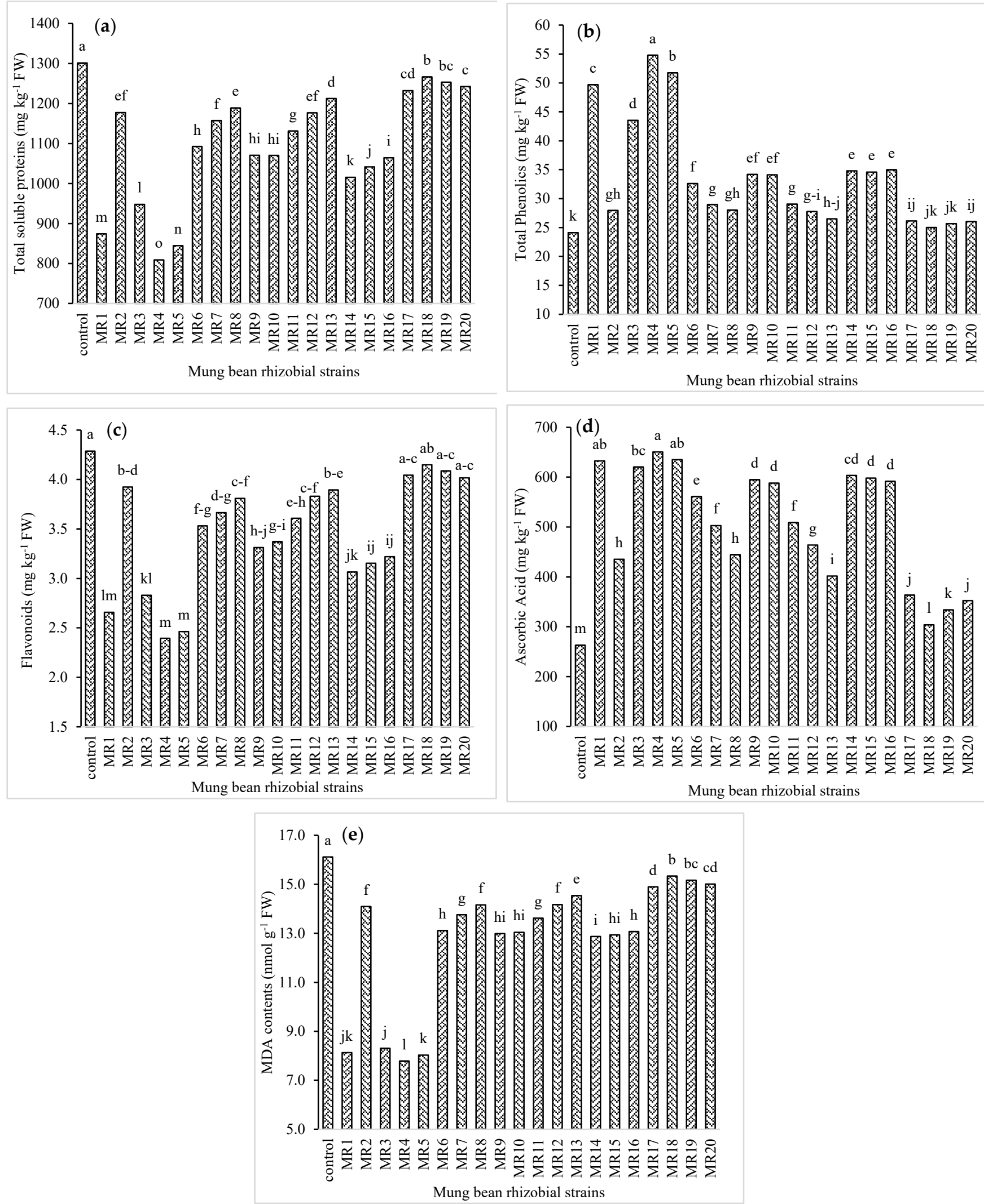

Figure 4. Impact of rhizobial inoculation on biochemical properties of mung bean under gnotobiotic conditions: (a) total soluble proteins; (b) total phenolics; (c) flavonoids; (d) ascorbic acid; (e) MDA contents (average of 3 replicates). Means sharing the same letters are statistically at par where $p=0.05$. 
Data regarding ascorbic acid concentrations are also shown in Figure $4 \mathrm{~d}$, which indicates that the lowest concentration of ascorbic acid was found in uninoculated plants, while the highest concentration was recorded in MR4 (650.5 $\left.\mathrm{mg} \mathrm{kg}^{-1} \mathrm{FW}\right)$ inoculated plants followed by MR5, MR1, and MR3. Inoculation of mung bean with rhizobial strains also produced significantly positive results, as MR4 inoculation produced $52 \%$ less MDA contents (Figure 4e) as compared to uninoculated control, which produced the highest MDA contents among all treatments.

\subsection{Selection of Rhizobial Isolates of Mung Bean}

Based on the results of growth promotion, nodulation ability, and physiological and biochemical characteristics recorded in an experimental trial conducted under gnotobiotic conditions, four rhizobial isolates (MR1, MR3, MR4, and MR5) were selected using cluster and principal component analysis. Factor coordinates of mung bean rhizobial isolates based on growth promotion and nodulation ability under gnotobiotic conditions are presented in Table 1. The maximum coordinate value (6.228) was observed due to MR4, followed by MR5 with 6.067, MR3 with 4.397, and MR1 with 4.246 F1 value (Table 1 ). The factorial plane clearly shows their unique behavior in the growth promotion and nodulation of mung bean. Further, these strains also fell under the same group in cluster analysis, with the highest similarity index (Figures 5 and 6).

Table 1. Factor coordinates of rhizobial isolates based on growth promotion and nodulation ability of mung bean under gnotobiotic conditions.

\begin{tabular}{|c|c|c|c|c|c|}
\hline Observation & F1 & F2 & F3 & F4 & F5 \\
\hline Control & -5.763 & 1.515 & 1.093 & 0.292 & -0.090 \\
\hline MR1 & 4.246 & -0.137 & 0.656 & -0.152 & 0.088 \\
\hline MR2 & 0.179 & 0.618 & -0.989 & -0.210 & 0.296 \\
\hline MR3 & 4.397 & -0.269 & -0.301 & 0.319 & 0.130 \\
\hline MR4 & 6.228 & 0.109 & 0.110 & 0.545 & -0.238 \\
\hline MR5 & 6.067 & 0.039 & -0.287 & -0.133 & -0.012 \\
\hline MR6 & 0.025 & -0.417 & 0.614 & 0.324 & 0.212 \\
\hline MR7 & -1.006 & -0.579 & 0.315 & 0.090 & 0.400 \\
\hline MR8 & -2.720 & -1.460 & 0.187 & -0.055 & 0.070 \\
\hline MR9 & 0.421 & -0.138 & 0.228 & 0.003 & -0.321 \\
\hline MR10 & 1.045 & 1.064 & 0.029 & -0.754 & 0.093 \\
\hline MR11 & -0.355 & 1.563 & 0.082 & 0.012 & 0.034 \\
\hline MR12 & -1.368 & -0.417 & 0.047 & -0.022 & 0.106 \\
\hline MR13 & -1.459 & 0.597 & -0.764 & 0.197 & -0.282 \\
\hline MR14 & -0.630 & -0.281 & 0.792 & -0.194 & -0.131 \\
\hline MR15 & 0.650 & -0.336 & 0.338 & -0.220 & -0.080 \\
\hline MR16 & -0.066 & -0.342 & 0.330 & -0.386 & -0.234 \\
\hline MR17 & -1.524 & 1.079 & -0.518 & 0.292 & 0.234 \\
\hline MR18 & -3.275 & -1.111 & -0.294 & 0.109 & 0.005 \\
\hline MR19 & -2.598 & -0.192 & -1.134 & -0.058 & -0.255 \\
\hline MR20 & -2.496 & -0.904 & -0.536 & 0.002 & -0.027 \\
\hline
\end{tabular}




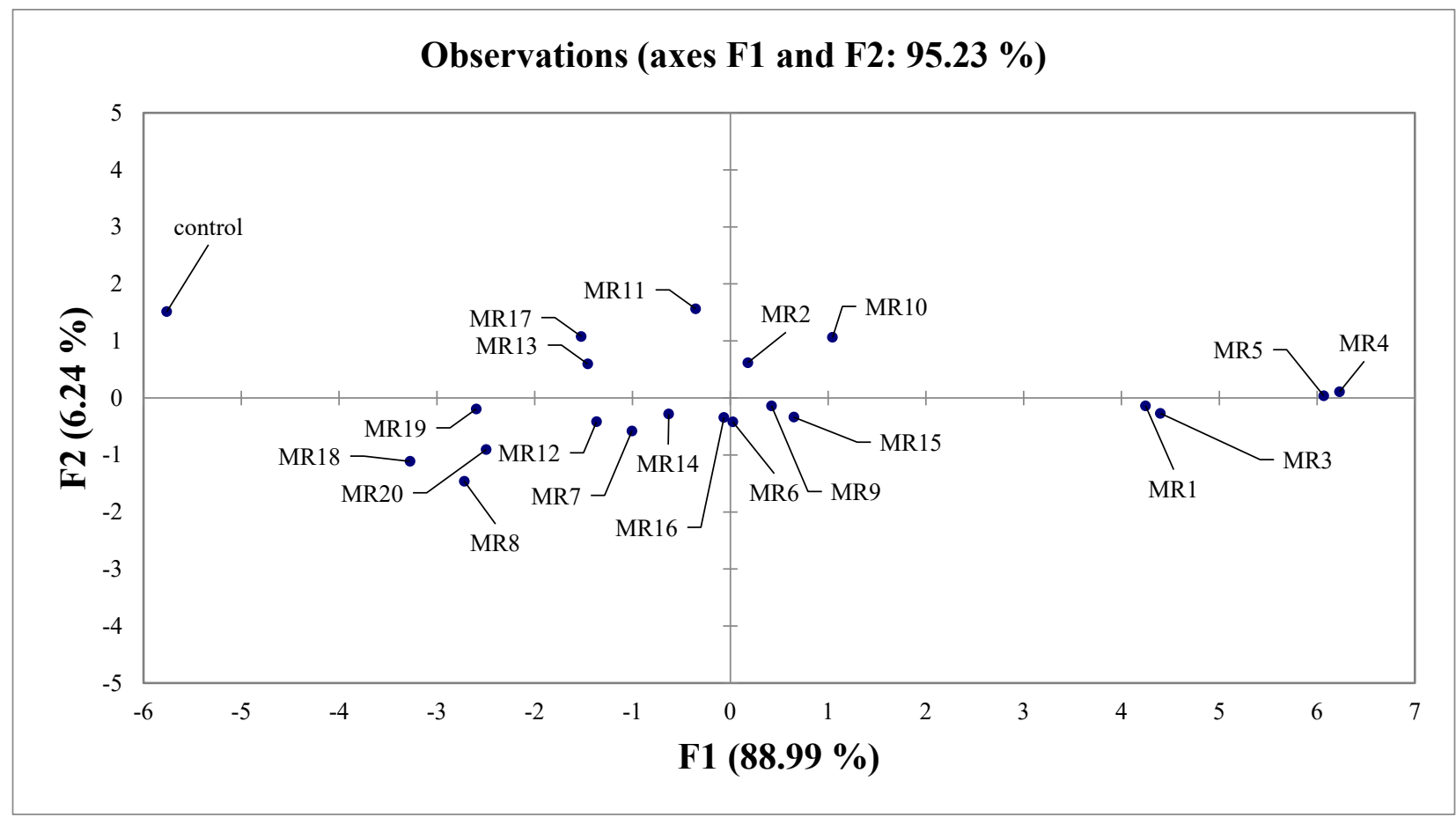

Figure 5. Principal component scores for mung bean rhizobial isolates based upon their performance in growth promotion and nodulation ability of mung bean under gnotobiotic conditions.

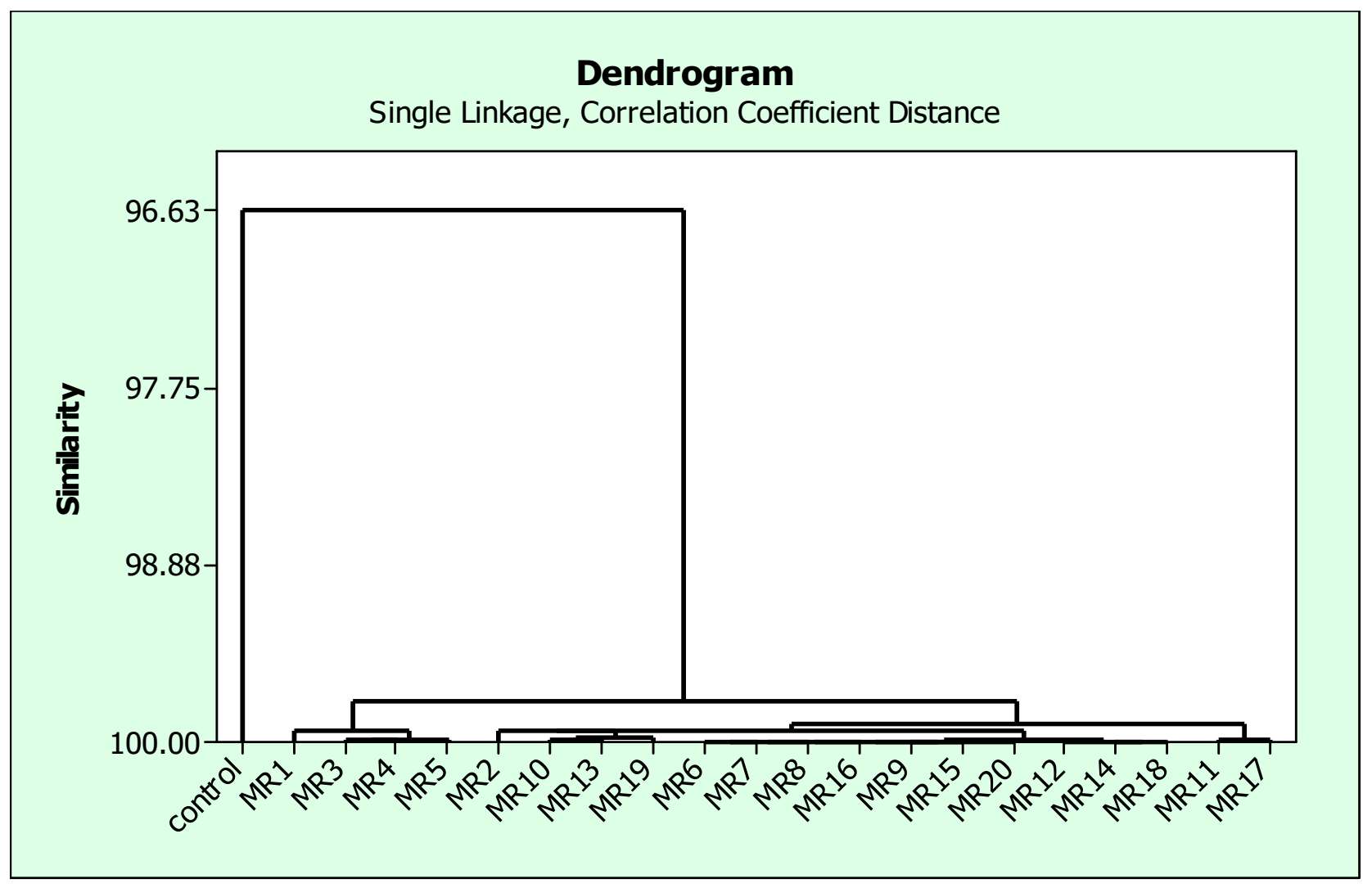

Figure 6. Cluster analysis showing groups of rhizobial isolates based upon their performance in growth promotion and nodulation ability of mung bean under gnotobiotic conditions. 


\subsection{Identification and Biochemical Characterization of the Selected Strains}

Identification was made by isolating them from the roots of mung beans and then re-inoculating them with the seeds of the mung bean under controlled environments, which triggered nodulation. As a result, the strains were confirmed to be Rhizobium phaseoli. Based on performance, four rhizobial strains were selected, and siderophore production, auxin production, chitinase activity, ACC-deaminase activity, root colonization ability, and phosphate solubilization were among the features studied. Table 2 lists the morphological and biochemical characteristics of the best-performing rhizobial strains. All the four selected rhizobial isolates (MR1, MR3, MR4, and MR5) depicted spherical colonies of milky white color and glossy look, being Gram-negative rods (Table 2). These strains were capable of auxin production and phosphate solubilization and demonstrated chitinase, oxidase, and exopolysaccharide activity. All the strains were capable of producing siderophore except MR3, while MR4 and MR5 were positive in organic acid production only (Table 2).

Table 2. Characterization of selected rhizobial strains (Rhizobium phaseoli).

\begin{tabular}{|c|c|c|c|c|}
\hline Codes & MR1 & MR3 & MR4 & MR5 \\
\hline Strains & Rhizobium phaseoli & Rhizobium phaseoli & Rhizobium phaseoli & Rhizobium phaseoli \\
\hline Cell shape & Rod-shaped & Rod-shaped & Rod-shaped & Rod-shaped \\
\hline Colony color & Milky white & Milky white & Milky white & Milky white \\
\hline Colony appearance & Shiny & Shiny & Shiny & Shiny \\
\hline Colony shape & Round & Round & Round & Round \\
\hline Gram's test & Negative & Negative & Negative & Negative \\
\hline Oxidase test & Positive & Positive & Positive & Positive \\
\hline Catalase test & Positive & Positive & Positive & Positive \\
\hline $\begin{array}{c}\text { Exoplysaccahride } \\
\text { activity }\end{array}$ & Positive & Positive & Positive & Positive \\
\hline Auxin biosynthesis & Highly positive & Highly positive & Highly positive & Highly positive \\
\hline Chitinase activity & Positive & Positive & Positive & Positive \\
\hline $\begin{array}{c}\text { Phosphate } \\
\text { solubilization }\end{array}$ & Positive & Positive & Positive & Positive \\
\hline $\begin{array}{l}\text { Siderophore } \\
\text { production }\end{array}$ & Positive & Negative & Positive & Positive \\
\hline $\begin{array}{l}\text { Organic acid } \\
\text { production }\end{array}$ & Negative & Negative & Positive & Positive \\
\hline
\end{tabular}

IAA synthesizing ability of the best-performing strains was tested at $35^{\circ} \mathrm{C}$, which showed significant results with notable variations in the data (Figure 7a), ranging from 9.2 to $16.7 \mu \mathrm{g} \mathrm{mL}^{-1}$ and 23.0 to $30.0 \mu \mathrm{g} \mathrm{mL}^{-1}$ in the absence and presence of L-Trp medium respectively. Gibberellin (GA) producing ability of these strains was also checked at $35^{\circ} \mathrm{C}$, and it was found that strain MR5 produced the highest value of gibberellin $\left(131.04 \mu \mathrm{gL} \mathrm{m}^{-1}\right)$ among all the tested strains, followed by MR4, MR1, and MR3 producing 125.94, 118.20, and $111.92 \mu \mathrm{g} \mathrm{mL}^{-1} \mathrm{GA}$, respectively (Figure $7 \mathrm{~b}$ ). The flavonoid production ability of all the selected strains was also evaluated in vitro (Figure $7 \mathrm{~b}$ ). The study revealed that maximum flavonoid $\left(147.45 \mu \mathrm{g} \mathrm{mL}^{-1}\right)$ was produced by MR5, while minimum flavonoid $\left(80.20 \mu \mathrm{g} \mathrm{mL}^{-1}\right)$ was produced by MR3 (Figure $7 \mathrm{~b}$ ). A plate assay was used to examine the ability of the best performing rhizobial strains to solubilize $\mathrm{ZnO}$ and $\mathrm{ZnCO}_{3}$. Figure $7 \mathrm{c}$ shows that $\mathrm{ZnO}$ and $\mathrm{ZnCO}_{3}$ solubilization indexes of MR5 were highest among the four isolates, having values of 3.2 and 3.63, respectively. Data in Figure 7c also indicates that $\mathrm{ZnCO}_{3}$ solubilization index ranged from 2.61 to 3.63 , and $\mathrm{ZnO}$ solubilization index ranged from 2.3 to 3.2. All the four isolates selected based on growth promotion and other attributes 
also proved their phosphorus solubilization ability by demonstrating P solubilization index ranging from 2.18 to 3.03, with the highest value of 3.03 tagged with MR5 strain (Figure 7c).
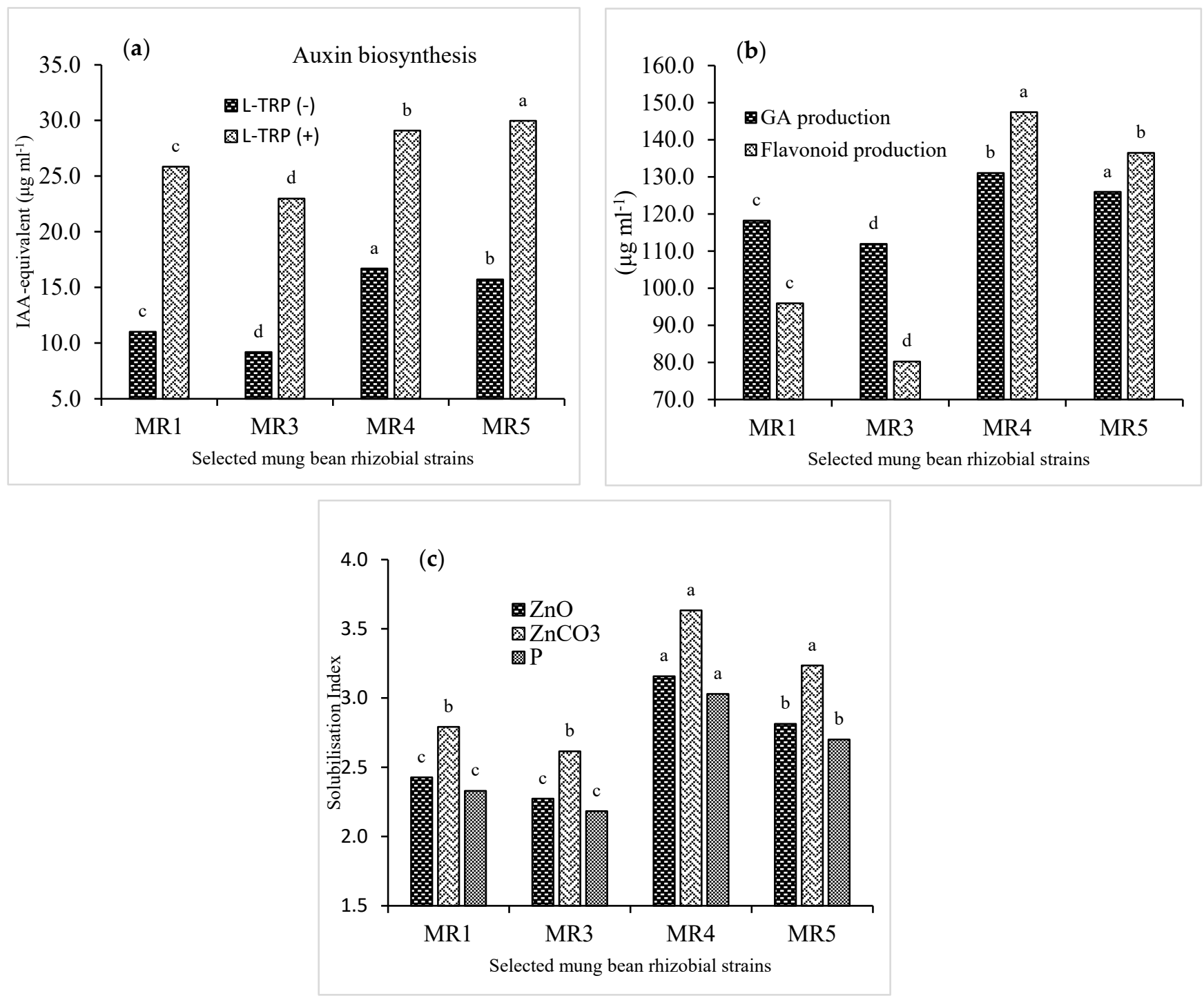

Figure 7. Biochemical Characteristics of selected mung bean rhizobial strains under gnotobiotic conditions: (a) auxin biosynthesis; (b) gibberellin and flavanoid production; (c) zinc and phosphorus solubilization index (average of 3 replicates). Means sharing the same letters are statistically at par where $p=0.05$.

\section{Discussion}

By forming a symbiotic association between rhizobia and plants, biological nitrogen fixation (BNF) plays a critical role in promoting the growth of legumes. The majority of rhizobial cultures used in our experiment under gnotobiotic conditions improved mung bean growth, but to varying degrees of efficiency. This variation in their growth promotion could be attributable to auxin, gibberellins, and flavonoid and other biomolecules production by the rhizobia [38]. Previous research has also demonstrated a variable response to rhizobial inoculation for improving lentil, chickpea, and pea growth [39].

In the same way, improvements were reported in the production of dry matter due to inoculation of rhizobia [40]. An increase in plant growth and mineral nutrient uptake due to auxin production by rhizobial isolates has also been reported by Etesami et al. [39]. It was observed in the present study that some of the rhizobial isolates did not improve the growth of mung bean seedlings under gnotobiotic conditions. This kind of failure in 
growth promotion activity might be due to a lack of efficiency by Rhizobium strains to colonize the root surface [41]. Non-significant improvement in growth parameters has also been reported by Rhijn et al. [42] in pea (Pisum sativum) and alfalfa (Medicago sativa L.) plants in response to Rhizobium inoculants. This may be due to insufficient or absence of exopolysaccharides to rhizobial strains due to mutation or some unknown reasons.

In the present study, rhizobial inoculation significantly improved physiological parameters of mung bean by most of the strains, with top-of-the-line performance by MR5, MR4, MR3, and MR1, which is justified by the fact that besides nitrogen fixation, plant-associated rhizobia may also improve plant physiology by increasing nutrient bioavailability and uptake [43], siderophores and osmolytes production [44,45], ACC deaminase regulation [14], and phytohormone production [46]. Improvements in photosynthetic attributes of mung bean in the present study is supported by the research of other scientists [47] who documented that rhizobial inoculation has the ability to increase chlorophyll concentrations in agricultural plants, which leads to improved productivity as a result of better photosynthetic activity. Results of the present study in terms of physiology and photosynthetic characteristics are also in line with the findings [48] that found that in maize crop chlorophyll contents, stomatal conductance of water, transpiration rate, relative water contents, photosynthetic rate, nutrients uptake, and intrinsic water use efficiency were improved under both stressed and normal conditions.

According to the results of the present experiment, Rhizobium inoculation improved physiological characteristics of plants that lead to maximum growth and production. In a study [49], rhizobium alone and in combination with Pseudomonas strains greatly improved the chlorophyll contents, photosynthetic rate, relative water contents, transpiration rate, carbon assimilation rate and stomatal conductance of water in mung bean, reducing the negative impacts of salinity. This improvement in plant's growth, physiology and quality as in case of present study was inline [50] might be through a variety of ways including reducing the endogenous level of ethylene. Ref. [51] reported an increase in leaf chlorophyll contents in both glasshouse and field conditions with the application of rhizobia which supports current findings where increase in chlorophyll contents of mung bean was recorded.

All the rhizobial strains, especially the selected strains in the present experiment, demonstrated better results [52] in terms of increases in photosynthetic leaf area, chlorophyll content, and relative water content following inoculation with rhizobium strains that produce ACC deaminase and IAA, or that solubilize phosphate. Findings of current research are also in line with the findings of [53], which found that Rhizobium laguerreae, a plant-growth-promoting microorganism, was found to have favorable effects on vegetative parameters of leafy vegetable in comparison to uninoculated control, such as chlorophyll, leaf size, leaf weight, leaf number, and nitrogen content.

As found in the present study, inoculating legumes with Rhizobium increases the amount of chlorophyll in their leaves [54]. Similar results were reported by [55] in their field and glasshouse research on soybean and cowpea, in which B. japonicum inoculation and supplementation of phosphate significantly boosted leaf chlorophyll contents. Significantly higher growth rates in the current experiment are owing to the fact that an increase in chlorophyll concentration leads to an increase in photosynthetic processes, leading to an increase in sugar production for plant growth and development [51].

Because IAA is the most prevalent and important auxin in plants, it plays a critical function in plant growth regulation. All the four different rhizobial strains selected based on their performance in the experiment had produced IAA equivalents and had a significant impact on plant development by modifying the endogenous auxin produced by the plants [56]. Phytohormones such as gibberellins play a major role in plant morphology alteration. As a result, they are said to promote stem growth, flower and fruit development, dormancy reversal, and seed germination in plants. Five gibberellins producing rhizobacteria were isolated [57], which produced more gibberellins at $30^{\circ} \mathrm{C}$ as well as $40{ }^{\circ} \mathrm{C}$. In plant-microbe interactions, flavonoids are the most important signaling molecule. In addi- 
tion to colonization in the rhizosphere, flavonoid synthesis is a key plant-growth-promoting feature demonstrated by many soil microorganisms that induce nod gene expression and increase nodulation [56].

Among other minerals, plants need zinc to flourish, and it can be found in a variety of forms, such as smithsonite $\left(\mathrm{ZnCO}_{3}\right), \mathrm{ZnS}$ (sphalerite), franklinite $\left(\mathrm{ZnFe}_{2} \mathrm{O}_{4}\right)$, zincite $(\mathrm{ZnO})$, and zinkosite $\left(\mathrm{ZnSO}_{4}\right)$ [58]. Field crop yields such as wheat, rice, maize, and barley are increased by inoculation of $\mathrm{Zn}$ solubilizer rhizobacterial strains, which increase the availability of phosphorus (P) to plants [59]. Because PSBs (phosphate-solubilizing bacteria) produce plant growth chemicals, these molecules likely enhance plant growth through their direct impact on metabolic processes. As a result of this, the lateral roots and root hairs proliferate, leading to an increase in nutrient absorption surfaces [60]. Therefore, screening of effective rhizobial strains under controlled conditions based on growth promotion and verification by the production of biochemical molecules that help the plants in growth promotion and establishment of nodules may be a beneficial strategy for the selection of symbiotically effective rhizobial strains.

\section{Conclusions}

The outcomes of this study revealed that inoculation of mung bean with distinct and healthy strains improved the growth, biomass production, physiology, and biochemical traits which depicts a significant yield of the crop when grown to maturity. The results of this research are also very useful for researchers to further investigate the selected strains to explore their potential under specific environmental conditions. Furthermore, the results of the present study are useful to convince farmers of mung bean to inoculate their crops with healthy rhizobial strains instead of depending upon the native strains present in their fields and synthetic nitrogenous fertilizers. It is concluded from this research experiment that the use of specific and effective rhizobial inoculation to mung bean produces significant improvement in all indicators of crop production, which confirms this practice of inoculation as a major component of sustainable production.

Author Contributions: Conceptualization, A.M.; methodology, A.M.; software, M.I.; formal analysis, A.M., M.K. and M.I.; investigation, T.S., S.H. and H.M.A.; resources, M.K., M.I. and H.M.A.; writingoriginal draft preparation, A.M.; writing-review and editing, H.M.A., Q.A., S.Y. and M.Z.M.S.; supervision, M.K. and Q.A.; project administration, S.Y.; funding acquisition, A.M., M.I. and H.M.A. All authors have read and agreed to the published version of the manuscript.

Funding: We are thankful to the Higher Education Commission (HEC), Pakistan (Pin 2Av1-131). The authors further acknowledge the financial support by Researchers Supporting Project number (RSP-2021/123) King Saud University, Riyadh, Saudi Arabia.

Institutional Review Board Statement: Not applicable.

Informed Consent Statement: Not applicable.

Data Availability Statement: Not applicable.

Acknowledgments: The authors acknowledge the financial support by Researchers Supporting Project number (RSP-2021/123) King Saud University, Riyadh, Saudi Arabia.

Conflicts of Interest: The authors declare no conflict of interest. The funders had no role in the design of the study; in the collection, analyses, or interpretation of data; in the writing of the manuscript, or in the decision to publish the results.

\section{References}

1. Glick, B.R. Bacteria with ACC deaminase can promote plant growth and help to feed the world. Microbiol. Res. 2014, 169, 30-39. [CrossRef]

2. Laranjo, M.; Alexandre, A.; Oliveira, S. Legume growth-promoting rhizobia: An overview on the Mesorhizobium genus. Microbiol. Res. 2014, 169, 2-17. [CrossRef]

3. Glick, B.R. Plant growth-promoting bacteria: Mechanisms and applications. Scientifica 2012, 2012, 963401. [CrossRef] 
4. Oldroyd, G.E. Speak, friend, and enter: Signalling systems that promote beneficial symbiotic associations in plants. Nat. Rev. Microbiol. 2013, 11, 252-263. [CrossRef]

5. Jensen, E.S.; Peoples, M.B.; Boddey, R.M.; Gresshoff, P.M.; Hauggaard-Nielsen, H.; Alves, B.J.; Morrison, M.J. Legumes for mitigation of climate change and the provision of feedstock for biofuels and biorefineries. A review. Agron. Sustain. Dev. 2012, 32, 329-364. [CrossRef]

6. Lupwayi, N.; Clayton, G.; Hanson, K.; Rice, W.; Biederbeck, V. Endophytic rhizobia in barley, wheat and canola roots. Can. J. Plant Sci. 2004, 84, 37-45. [CrossRef]

7. Perret, X.; Staehelin, C.; Broughton, W.J. Molecular basis of symbiotic promiscuity. Microbiol. Mol. Biol. Rev. 2000, 64, 180-201. [CrossRef] [PubMed]

8. Kanwal, U.; Ibrahim, M.; Abbas, F.; Yamin, M.; Jabeen, F.; Shahzadi, A.; Farooque, A.A.; Imtiaz, M.; Ditta, A.; Ali, S. Phytoextraction of Lead Using a Hedge Plant [Alternanthera bettzickiana (Regel) G. Nicholson]: Physiological and Biochemical Alterations through Bioresource Management. Sustainability 2021, 13, 5074. [CrossRef]

9. Stephens, J.; Rask, H. Inoculant production and formulation. Field Crop. Res. 2000, 65, 249-258. [CrossRef]

10. Chernin, L.; Glick, B.R. The use of ACC deaminase to increase the tolerance of plants to various phytopathogens. In Bacteria in Agrobiology: Stress Management; Springer: Berlin, Germany, 2012; pp. 279-299.

11. Berg, G. Plant-microbe interactions promoting plant growth and health: Perspectives for controlled use of microorganisms in agriculture. Appl. Microbiol. Biotechnol. 2009, 84, 11-18. [CrossRef] [PubMed]

12. Bal, H.B.; Das, S.; Dangar, T.K.; Adhya, T.K. ACC deaminase and IAA producing growth promoting bacteria from the rhizosphere soil of tropical rice plants. J. Basic Microbiol. 2013, 53, 972-984. [CrossRef]

13. Dakora, F.D.; Matiru, V.; Kanu, A.S. Rhizosphere ecology of lumichrome and riboflavin, two bacterial signal molecules eliciting developmental changes in plants. Front. Plant Sci. 2015, 6, 700. [CrossRef] [PubMed]

14. Duan, J.; Müller, K.M.; Charles, T.C.; Vesely, S.; Glick, B.R. 1-aminocyclopropane-1-carboxylate (ACC) deaminase genes in rhizobia from southern Saskatchewan. Microb. Ecol. 2009, 57, 423-436. [CrossRef] [PubMed]

15. Shokri, D.; Emtiazi, G. Indole-3-acetic acid (IAA) production in symbiotic and non-symbiotic nitrogen-fixing bacteria and its optimization by Taguchi design. Curr. Microbiol. 2010, 61, 217-225. [CrossRef]

16. Avis, T.J.; Gravel, V.; Antoun, H.; Tweddell, R.J. Multifaceted beneficial effects of rhizosphere microorganisms on plant health and productivity. Soil Biol. Biochem. 2008, 40, 1733-1740. [CrossRef]

17. Thakur, A.; Panwar, J. Effect of rhizobium-VAM interactions on growth and yield in mungbean (Vigna radiata (L) Wilczek) under field conditions. Indian J. Plant Physiol. 1995, 38, 62-65.

18. PARC. National Coordinated Program for Sugar and Food Legume Crops. 2021. Available online: http://www.parc.gov.pk/ index.php/en/national-coordinated-research-system/108-national-coordinated-research-systems/324-national-coordinatedprogram-for-sugar-and-food-legume-crops (accessed on 2 July 2021).

19. Abd-Alla, M.H.; Morsy, F.M.; El-Enany, A.-W.E.; Ohyama, T. Isolation and characterization of a heavy-metal-resistant isolate of Rhizobium leguminosarum bv. viciae potentially applicable for biosorption of Cd2+ and Co2+. Int. Biodeterior. Biodegrad. 2012, 67, 48-55. [CrossRef]

20. Ben-Asher, J.; Tsuyuki, I.; Bravdo, B.-A.; Sagih, M. Irrigation of grapevines with saline water: I. Leaf area index, stomatal conductance, transpiration and photosynthesis. Agric. Water Manag. 2006, 83, 13-21. [CrossRef]

21. Hussain, F.; Bronson, K.; Yadvinder, S.; Singh, B.; Peng, S. Use of chlorophyll meter sufficiency indices for nitrogen management of irrigated rice in Asia. Agron. J. 2000, 92, 875-879.

22. Arnon, D.I. Copper enzymes in isolated chloroplasts. Polyphenoloxidase in Beta vulgaris. Plant Physiol. 1949, 24, 1. [CrossRef]

23. Aery, N. Manual of Environmental Analysis; Ane Books Pvt Ltd.: New Delhi, India, 2010.

24. Bradford, M.M. A rapid and sensitive method for the quantitation of microgram quantities of protein utilizing the principle of protein-dye binding. Anal. Biochem. 1976, 72, 248-254. [CrossRef]

25. Cakmak, I.; Horst, W.J. Effect of aluminium on lipid peroxidation, superoxide dismutase, catalase, and peroxidase activities in root tips of soybean (Glycine max). Physiol. Plant. 1991, 83, 463-468. [CrossRef]

26. Sarwar, M.; Arshad, M.; Martens, D.A.; Frankenberger, W. Tryptophan-dependent biosynthesis of auxins in soil. Plant Soil 1992, 147, 207-215. [CrossRef]

27. Borrow, A.; Brian, P.; Chester, V.; Curtis, P.; Hemming, H.; Henehan, C. Gibberellic acid, a metabolic product of the fungus Gibberella fujikuroi: Some observations on its production and isolation. J. Sci. Food Agric. 1955, 6, 340-348. [CrossRef]

28. Zhishen, J.; Mengcheng, T.; Jianming, W. The determination of flavonoid contents in mulberry and their scavenging effects on superoxide radicals. Food Chem. 1999, 64, 555-559. [CrossRef]

29. Fasim, F.; Ahmed, N.; Parsons, R.; Gadd, G.M. Solubilization of zinc salts by a bacterium isolated from the air environment of a tannery. FEMS Microbiol. Lett. 2002, 213, 1-6. [CrossRef] [PubMed]

30. Mehta, S.; Nautiyal, C.S. An efficient method for qualitative screening of phosphate-solubilizing bacteria. Curr. Microbiol. 2001, 43, 51-56. [CrossRef] [PubMed]

31. Ramesh, A.; Sharma, S.K.; Sharma, M.P.; Yadav, N.; Joshi, O.P. Inoculation of zinc solubilizing Bacillus aryabhattai strains for improved growth, mobilization and biofortification of zinc in soybean and wheat cultivated in Vertisols of central India. Appl. Soil Ecol. 2014, 73, 87-96. [CrossRef] 
32. Schwyn, B.; Neilands, J. Universal chemical assay for the detection and determination of siderophores. Anal. Biochem. 1987, 160, 47-56. [CrossRef]

33. Ashraf, M.; Hasnain, S.; Berge, O.; Mahmood, T. Inoculating wheat seedlings with exopolysaccharide-producing bacteria restricts sodium uptake and stimulates plant growth under salt stress. Biol. Fertil. Soils 2004, 40, 157-162. [CrossRef]

34. Chernin, L.S.; Winson, M.K.; Thompson, J.M.; Haran, S.; Bycroft, B.W.; Chet, I. Chitinolytic activity in Chromobacterium violaceum: Substrate analysis and regulation by quorum sensing. J. Bacteriol. 1998, 180, 4435-4441. [CrossRef]

35. MacFaddin, J.F. Biochemical Tests for Identification of Medical Bacteria; Lippincott Williams: Philadelphia, PA, USA, 2000.

36. Nutman, P. A Manual for the Practical Study of Root-Nodule Bacteria; Wiley-Blackwell: Hoboken, NJ, USA, 1970.

37. Steel, R.; Torrie, J.; Dicky, D. Principles and Procedures of Statistics. Multiple Comparisons; McGraw Hill Book Co.: New York, NY, USA, 1997.

38. Huang, H.; Erickson, R. Effect of seed treatment with Rhizobium leguminosarum on Pythium damping-off, seedling height, root nodulation, root biomass, shoot biomass, and seed yield of pea and lentil. J. Phytopathol. 2007, 155, 31-37. [CrossRef]

39. Etesami, H.; Alikhani, H.A.; Akbari, A.A. Evaluation of plant growth hormones production (IAA) ability by Iranian soils rhizobial strains and effects of superior strains application on wheat growth indexes. World Appl. Sci. J. 2009, 6, 1576-1584.

40. Dey, R.; Pal, K.; Bhatt, D.; Chauhan, S. Growth promotion and yield enhancement of peanut (Arachis hypogaea L.) by application of plant growth-promoting rhizobacteria. Microbiol. Res. 2004, 159, 371-394. [CrossRef]

41. Jadhav, R.; Thaker, N.; Desai, A. Involvement of the siderophore of cowpea Rhizobium in the iron nutrition of the peanut. World J. Microbiol. Biotechnol. 1994, 10, 360-361. [CrossRef]

42. Van Rhijn, P.; Fujishige, N.A.; Lim, P.O.; Hirsch, A.M. Sugar-binding activity of pea lectin enhances heterologous infection of transgenic alfalfa plants by Rhizobium leguminosarum biovar viciae. Plant Physiol. 2001, 126, 133-144. [CrossRef] [PubMed]

43. Afzal, A.; Bano, A. Rhizobium and phosphate solubilizing bacteria improve the yield and phosphorus uptake in wheat (Triticum aestivum). Int. J. Agric. Biol. 2008, 10, 85-88.

44. Grover, M.; Ali, S.Z.; Sandhya, V.; Rasul, A.; Venkateswarlu, B. Role of microorganisms in adaptation of agriculture crops to abiotic stresses. World J. Microbiol. Biotechnol. 2011, 27, 1231-1240. [CrossRef]

45. Saïdi, S.; Chebil, S.; Gtari, M.; Mhamdi, R. Characterization of root-nodule bacteria isolated from Vicia faba and selection of plant growth promoting isolates. World J. Microbiol. Biotechnol. 2013, 29, 1099-1106. [CrossRef] [PubMed]

46. Chandra, S.; Choure, K.; Dubey, R.C.; Maheshwari, D.K. Rhizosphere competent Mesorhizobiumloti MP6 induces root hair curling, inhibits Sclerotinia sclerotiorum and enhances growth of Indian mustard (Brassica campestris). Braz. J. Microbiol. 2007, 38, 124-130. [CrossRef]

47. Elkoca, E.; Turan, M.; Donmez, M.F. Effects of single, dual and triple inoculations with Bacillus subtilis, Bacillus megaterium and Rhizobium leguminosarum bv. Phaseoli on nodulation, nutrient uptake, yield and yield parameters of common bean (Phaseolus vulgaris 1. cv.'elkoca-05'). J. Plant Nutr. 2010, 33, 2104-2119. [CrossRef]

48. Hussain, M.B.; Mahmood, S.; Ahmed, N.; Nawaz, H. Rhizobial inoculation for improving growth physiology, nutrition and yield of maize under drought stress conditions. Pak. J. Bot. 2018, 50, 1681-1689.

49. Ahmad, M.; Zahir, Z.A.; Khalid, M.; Nazli, F.; Arshad, M. Efficacy of Rhizobium and Pseudomonas strains to improve physiology, ionic balance and quality of mung bean under salt-affected conditions on farmer's fields. Plant Physiol. Biochem. 2013, 63, 170-176. [CrossRef] [PubMed]

50. Ahmad, M.; Zahir, Z.A.; Asghar, H.N.; Asghar, M. Inducing salt tolerance in mung bean through coinoculation with rhizobia and plant-growth-promoting rhizobacteria containing 1-aminocyclopropane-1-carboxylate deaminase. Can. J. Microbiol. 2011, 57, 578-589. [CrossRef]

51. Bambara, S.K.; Ndakidemi, P.A. Effects of Rhizobium inoculation, lime and molybdenum on photosynthesis and chlorophyll content of Phaeseolus vulgaris L. Afr. J. Microbiol. Res. 2009, 3, 791-798.

52. Saghafi, D.; Ghorbanpour, M.; Lajayer, B.A. Efficiency of Rhizobium strains as plant growth promoting rhizobacteria on morpho-physiological properties of Brassica napus L. under salinity stress. J. Soil Sci. Plant Nutr. 2018, 18, 253-268. [CrossRef]

53. Jiménez-Gómez, A.; Flores-Félix, J.D.; García-Fraile, P.; Mateos, P.F.; Menéndez, E.; Velázquez, E. Probiotic activities of Rhizobium laguerreae on growth and quality of spinach. Sci. Rep. 2018, 8, 1-10. [CrossRef]

54. Tairo, E.V.; Ndakidemi, P.A. Bradyrhizobium japonicum inoculation and phosphorus supplementation on growth and chlorophyll accumulation in soybean (Glycine max L.). Am. J. Plant Sci. 2013, 4, 40398. [CrossRef]

55. Nyoki, D.; Ndakidemi, P.A. Effects of phosphorus and Bradyrhizobium japonicum on growth and chlorophyll content of cowpea (Vigna unguiculata (L) Walp). J. Exp. Agric. Int. 2014, 1120-1136. [CrossRef]

56. Routray, S.; Khanna, V. Characterization of rhizobacteria for multiple plant growth promoting traits from mung bean rhizosphere. Int. J. Curr. Microbiol. App. Sci. 2018, 7, 2264-2269. [CrossRef]

57. Kaur, G.; Khanna, V. Evaluation of thermotolerant rhizobacteria for multiple plant growth promoting traits from pigeonpea rhizosphere. J. Appl. Nat. Sci. 2017, 9, 920-923. [CrossRef]

58. Hafeez, F.Y.; Abaid-Ullah, M.; Hassan, M.N. Plant growth-promoting rhizobacteria as zinc mobilizers: A promising approach for cereals biofortification. In Bacteria in Agrobiology: Crop Productivity; Springer: Berlin, Germany, 2013; pp. $217-235$.

59. Chen, Y.; Rekha, P.; Arun, A.; Shen, F.; Lai, W.-A.; Young, C.C. Phosphate solubilizing bacteria from subtropical soil and their tricalcium phosphate solubilizing abilities. Appl. Soil Ecol. 2006, 34, 33-41. [CrossRef]

60. Shahab, S.; Ahmed, N.; Khan, N.S. Indole acetic acid production and enhanced plant growth promotion by indigenous PSBs. Afr. J. Agric. Res. 2009, 4, 1312-1316. 